\title{
Circulating level of heat shock protein 27 is elevated in dogs with mammary tumors
}

\author{
Rancy Birdi $^{1} \cdot$ B. V. Sunil Kumar ${ }^{1} \cdot$ Kuldip Gupta $^{2} \cdot$ Neeraj Kashyap $^{3} \cdot$ Ashwani Kumar $^{4}$
}

Received: 31 August 2018 / Accepted: 16 May 2019 / Published online: 22 May 2019

(c) King Abdulaziz City for Science and Technology 2019

\begin{abstract}
In the current study, we have synthesized canine recombinant Hsp27 in E. coli and raised hyperimmune serum against the protein in mice. Using the hyperimmune serum, an indirect ELISA was developed to estimate circulating levels of Hsp27 in dogs with various types of mammary neoplasia and to compare their levels with those of tumor-free apparently healthy dogs. The developed assay had a high specificity (83.3\%) and sensitivity (96.6\%) for a cut-off value of 0.45 with respect to histopathological examination in discriminating healthy dogs from those bearing mammary tumors. Serum Hsp27 levels were found to be significantly elevated in tumor subjects $(20.33 \pm 1.23 \mathrm{ng} / \mathrm{ml})$ as compared to healthy controls $(6.56 \pm 0.51 \mathrm{ng} / \mathrm{ml})$ and the increase in the Hsp27 levels was irrespective of mammary tumor histotypes. However, dogs with grade-II tumors had higher Hsp27 levels as compared to grade-I types. Therefore, Hsp27 can be exploited as one of the 'neoplastic signatures' of canine mammary tumors.
\end{abstract}

Keywords Heat shock protein $27 \cdot$ Canine mammary tumor $\cdot$ Over-expression $\cdot$ Diagnosis $\cdot$ Prognosis

\section{Introduction}

Mammary tumors are one of the most frequently diagnosed neoplasia in intact female dogs (Moe 2001). These tumors are mostly hormone-dependent and the risk of their occurrence increases after each estrus cycle. The incidence of mammary neoplasia is approximately three times more than that in women (Sunil Kumar and Kataria 2013). Cancers are often detected at their later stages owing to their

B. V. Sunil Kumar

drbvskumar@gmail.com

1 School of Animal Biotechnology, Guru Angad Dev Veterinary and Animal Sciences University, Ludhiana, Punjab 141004, India

2 Department of Veterinary Pathology, College of Veterinary Sciences, Guru Angad Dev Veterinary and Animal Sciences University, Ludhiana, Punjab 141004, India

3 Department of Animal Genetics and Breeding, College of Veterinary Sciences, Guru Angad Dev Veterinary and Animal Sciences University, Ludhiana, Punjab 141004, India

4 Department of Veterinary Surgery and Radiology, College of Veterinary Sciences, Guru Angad Dev Veterinary and Animal Sciences University, Ludhiana, Punjab 141004, India overlapping signs and symptoms with other diseases. However, a subject can be saved if neoplastic growth is detected at an earlier stage (Sunil Kumar et al. 2013). Reports suggest that certain proteins get over-expressed during mammary tumor development and get secreted into circulation; these proteins could be quantified for diagnosis and prognosis of the malady (Sunil Kumar et al. 2018).

Heat shock proteins (Hsp) are synthesized in all the organisms and act by mediating resistance to hyperthermia, thereby enabling the host to survive and recover from stressful conditions (Calderwood 2010). Their over-expression is implicated in tumor cell proliferation, differentiation, invasion, metastasis, cell death, and recognition by immune system.

Hsp27 belongs to the small heat shock protein family with a molecular weight of 25-27 kDa. During stress, phosphorylation downstream of the p38 mitogen-activated protein kinase (MAPK) pathway leads to activation of this small Hsp; however, it is not clear how it is up-regulated in cancer (Simioni et al. 2009). It is postulated that heat shock factor 1 (Hsf1) becomes activated in breast cancer and Hsp27 levels may elevate in response to this change (Calderwood et al. 2012). Hsp27 has been detected both in intracellular as well as extracellular milieu. The former possesses an anti-apoptotic activity through interaction with 
Bid or cytochrome-c (Bruey et al. 2000). Hsp27 does not bind to ATP, unlike other Hsps, a property that may make this molecule problematic for targeting smaller compounds (Calderwood 2010).

Several Hsps are implicated with the diagnosis and prognosis of specific cancers (Sunil Kumar et al. 2018), including Hsp27, which is also secreted into the circulation (Gruden et al. 2013). It has been elucidated by IHC that Hsp27 is over-expressed in canine mammary tumors (CMT) (Bongiovanni et al. 2014), but there are no data on estimation of serum Hsp27 in dogs with mammary tumors. In this pursuit, we tried to investigate if Hsp27 levels are altered in dogs bearing mammary tumors with respect to tumor-free healthy controls. In this context, the present experiment was conducted to heterologously express Hsp27 from CMT and develop rHSP27-based indirect ELISA for determining circulating levels of Hsp27 in dogs with mammary tumors to aid in diagnosis and prognosis of CMT.

\section{Materials and methods}

\section{Collection of tissues and serum samples}

Mammary tumor tissues $(n=30)$ were collected from different breeds of dogs (Pug, Mongrel, German Shepherd, Labrador) at the time of surgery carried out in the Department of Veterinary Surgery and Radiology of Guru Angad Dev Veterinary and Animal Sciences University, Ludhiana. Tissues were collected in RNAlater (Sigma, USA) and 10\% neutral buffered formalin (NBF) for RNA isolation and histopathological examination respectively.

Blood samples were collected from tumor-free apparently healthy dogs $(n=30)$, mammary tumor bearing dogs $(n=30)$, and from those afflicted with different non-infectious diseases $(n=30)$ (arthritis, fracture, skin tumor, gastritis, and perineal hernia). All the animals under investigation were non-pregnant, in the age group of 6-12 years (median 8.05 years), and the groups were breed and age matched. The permission for collecting samples and handling laboratory animals was granted by institutional animal ethics committee of Guru Angad Dev Veterinary and Animal Sciences University, Ludhiana, vide Edst no. IAEC/2017/734-760.

\section{Histopathology}

About $5 \mu \mathrm{m}$ tumor sections were cut using rotary microtome and mounted over clean glass slides for haematoxylin-eosin staining. All the tumors were classified based on World Health Organization (WHO) criteria for tumor classification (Misdrop et al. 1999) with slight modifications (Goldschmidt et al. 2011). The histological grades of CMT malignancy were also assessed (Goldschmidt et al. 2011).

\section{RNA isolation and CDNA synthesis}

Total RNA was isolated from CMT samples by TRIzol method (Chomczynski and Sacchi 1987). Furthermore, cDNA was synthesized from $1 \mu \mathrm{g}$ RNA using oligo dT primers and RevertAid premium first-strand cDNA synthesis kit (Thermo Scientific, USA) following the manufacturer's instructions. The cDNA was checked with PCR using $\beta$-actin-specific primers.

\section{Cloning of $h s p 27$ gene}

Using pick primer program in NCBI, oligonucleotide primers targeting canine $h s p 27$ gene (Genbank accession number: NM_001003295.2) were designed and custom synthesized from Integrated DNA Technologies (IDT). Restriction sites for the restriction enzymes Nco1 and Xho1 were incorporated at the $5^{\prime}$ ends of the forward and reverse primers, respectively, for directional cloning (AACCATGGTTG ACGCCCCGCACTTCTCTAA and AACTCGAGTGT GCAGGGACGGTCAGTGA). Due to incorporation of extra bases in the primers, the predicted amplicon size increased to $753 \mathrm{bp}$. A $25 \mu \mathrm{l}$ PCR reaction was prepared containing $1 \mu \mathrm{l}$ cDNA, $12.5 \mu \mathrm{l} 2 \times$ master mix (Hot Star high fidelity master mix, Qiagen, Germany) and $1 \mu \mathrm{l}$ each of $20 \mu \mathrm{M}$ forward and reverse primers. An initial denaturation at $95^{\circ} \mathrm{C}$ for $15 \mathrm{~min}$ followed by 35 cycles of denaturation $\left(94^{\circ} \mathrm{C}\right.$ for $1 \mathrm{~min}$ ), annealing $\left(55^{\circ} \mathrm{C}\right.$ for $\left.1 \mathrm{~min}\right)$ and extension $\left(72^{\circ} \mathrm{C}\right.$ for $1 \mathrm{~min}$ ), and a final extension step at $72{ }^{\circ} \mathrm{C}$ for $10 \mathrm{~min}$ were set for PCR. The amplicon, thus, obtained was resolved on $1.5 \%$ agarose gel along with $1 \mathrm{~kb}$ plus DNA ladder (Thermo Scientific, USA). Amplicon was further extracted from the agarose gel using quick gel extraction kit (Qiagen, Germany) following the manufacturer's instructions.

The prokaryotic expression vector pPROEx HTa and gel purified PCR product ( $h s p 27$ ) were digested separately using $N c o I$ and $\mathrm{XhoI}$ enzymes (New England Biologicals, UK). The digested insert and vector were ligated at $14{ }^{\circ} \mathrm{C}$ for overnight using T4 DNA ligase (Thermo Scientific, USA) and transformed into competent DH5 $\alpha$ cells. The transformed cells were plated on to Luria-Bertani (LB) agar plates supplemented with ampicillin $(100 \mu \mathrm{g} / \mathrm{ml})$ and were incubated at $37{ }^{\circ} \mathrm{C}$ overnight. The following day, positive clones harboring recombinant plasmids were selected and inoculated into LB broth (Himedia, India) containing ampicillin $(100 \mu \mathrm{g} / \mathrm{ml})$ and incubated at $37^{\circ} \mathrm{C}$. Plasmids were isolated from the overnight grown culture by alkaline lysis method (Sambrook and Russell 2001) and double digested with NcoI and XhoI restriction enzymes for confirmation of insert in the vector. Positive clones were custom sequenced and the sequence was submitted to NCBI. 


\section{Heterologous expression of recombinant Hsp27 and its purification}

The positive clone was sub-cultured in $100 \mathrm{ml} \mathrm{LB}$ broth containing ampicillin $(100 \mu \mathrm{g} / \mathrm{ml})$ till its absorbance reached 0.6. Expression of rHsp27 was induced with $1 \mathrm{mM}$ IPTG for $5 \mathrm{~h}$. Induced culture was centrifuged at $12,000 \times g$ for $30 \mathrm{~min}$ and the pellet thus obtained was resuspended in $15 \mathrm{ml}$ of lysis buffer $\left(100 \mathrm{mM} \mathrm{NaH} \mathrm{PO}_{4}\right.$, $100 \mathrm{mM}$ Tris-Cl, 8 M Urea, $\mathrm{pH}$ 8.0). Bacterial suspension was sonicated at $15 \mathrm{~Hz}$ with pulse on and off time of $30 \mathrm{~s}$ for a total of 20 cycles. The sonicated cell suspension was centrifuged at $12,000 \times g$ for $15 \mathrm{~min}$ and supernatant was passed through Ni-NTA agarose column (Qiagen, Germany). The column was washed three times with $30 \mathrm{ml}$ of wash buffer $\left(100 \mathrm{mM} \mathrm{NaH}_{2} \mathrm{PO}_{4}, 100 \mathrm{mM}\right.$ Tris-Cl, $8 \mathrm{M}$ Urea, pH 6.3). Finally, $10 \mathrm{ml}$ of elution buffer $(100 \mathrm{mM}$ $\mathrm{NaH}_{2} \mathrm{PO}_{4}, 100 \mathrm{mM}$ Tris-Cl, $8 \mathrm{M}$ Urea, $\mathrm{pH} 4.5$ ) was added to the column to elute bound proteins. The proteins were dialysed against $1 \times$ PBS to remove traces of urea. The proteins were also renatured using protein renaturation kit (Thermo Scientific, USA). The renatured proteins were collected as $0.5 \mathrm{ml}$ fractions in sterile microcentrifuge tubes and stored at $-20{ }^{\circ} \mathrm{C}$ till further use. Recombinant Hsp27 expression was checked by SDS-PAGE (Laemmli 1970) followed by western blotting (Towbin et al. 1979) using commercially available anti-canine Hsp27 antibodies.

\section{Production of hyperimmune sera against canine rHsp27 in mice}

For production of hyperimmune sera against $\mathrm{rHsp} 27$, ten mice were used. After an acclimatization period of 1 week, animals were used for immunization. The recombinant protein was mixed with equal quantity of Freund's complete adjuvant (Santacruz, USA) and inoculated subcutaneously in mice ( $50 \mu \mathrm{g}$ of protein/mice) for priming. Subsequently, booster doses were given on 7 th, 14th, 21st, and 28th days after priming with recombinant proteins mixed with Freund's incomplete adjuvant (Santacruz, USA). Test bleeding was done from tail veins of mice on 29th day to check the titre of the antibodies (Pandey et al. 2017). Final bleeding was done by cardiac puncture on 30th day, and sera were harvested and stored at $-20{ }^{\circ} \mathrm{C}$ until further use. Immunoglobulin $\mathrm{G}$ ( $\mathrm{IgG}$ ) was purified from mice hyperimmune sera by ammonium sulfate precipitation and ion-exchange chromatography (Talwar 1983). SDS-PAGE was carried out to check the purity of isolated mice IgG. Immuno-reactivity of the purified IgG against rHsp27 and circulating Hsp27 in mammary tumor-positive dog serum was checked by western blotting.

\section{Indirect ELISA}

IgG purified from the hyperimmune sera was used as primary antibody for indirect ELISA. The optimum dilution of primary antibody was selected by chequerboard titration against fixed dilution/concentration of recombinant antigen (Pandey et al. 2015).

Three flat-bottom polystyrene plates (Nunc) were coated separately with $50 \mu \mathrm{l}$ of test serum samples (serum from apparently healthy dogs, mammary tumor subjects, and those with other types of cancers and inflammatory diseases, respectively) diluted to $1: 10$ in $0.5 \mathrm{M}$ carbonate-bicarbonate buffer (pH 9.6) and incubated at $4{ }^{\circ} \mathrm{C}$ for $8 \mathrm{~h}$. A control panel consisting of positive antigen control (recombinant protein), negative antigen control (BSA), conjugate control (no detection antibody), and blank (only blocking buffer) was also incorporated in the plates. After $8 \mathrm{~h}$ of incubation, plates were washed thrice with $300 \mu$ phosphate-buffered saline-tween 20 (PBS-T) at room temperature for $5 \mathrm{~min}$ each to remove any unbound antigen. Unoccupied places in the wells were blocked with $200 \mu \mathrm{l}$ of blocking buffer (3\% skimmed milk and $2 \%$ nutrient gelatin in PBS) and placed at $4{ }^{\circ} \mathrm{C}$ for $6 \mathrm{~h}$. Following incubation and washing, $50 \mu \mathrm{l}$ of primary antibody diluted to 1:3200 in blocking buffer was added to the wells. Plates were incubated at $37{ }^{\circ} \mathrm{C}$ for $2 \mathrm{~h}$ and washed thrice with PBS-T. Next, $50 \mu \mathrm{l}$ secondary antibody (HRPO-conjugated anti-mice IgG, Sigma, USA), diluted to 1:5000 in blocking buffer was added and plates were again incubated at $37{ }^{\circ} \mathrm{C}$ for $1 \mathrm{~h}$. After final washing, $50 \mu \mathrm{l}$ of freshly prepared substrate/chromogen mixture [1 mg OPD (Sigma, St. Louis, USA) in $1 \mathrm{ml}$ of $0.1 \mathrm{M}$ citrate phosphate buffer (pH 5.0) mixed with $1 \mu \mathrm{l} / \mathrm{ml}$ of $30 \%$ hydrogen peroxide] was dispensed into the wells for color development. The color reaction was stopped by adding $50 \mu \mathrm{l}$ of $3 \mathrm{M} \mathrm{H}_{2} \mathrm{SO}_{4}$ to all the wells and absorbance (OD) was measured at a wavelength of $492 \mathrm{~nm}$ on ELISA reader (BioTek).

\section{Receiver-operating characteristic (ROC) analysis and reproducibility check}

Receiver-operating characteristic curves, the area under the ROC curve (AUC), test predictive values $( \pm)$, likelihood ratios ( \pm ), and optimal cut-off points (Greiner et al. 2000) were obtained by analyzing the data using the software MedCalc version 15.4.

For testing reproducibility of the developed assay, five random test serum samples (from mammary tumor-positive dogs) were selected. The developed ELISA was carried out with these samples in five different plates at different time intervals to determine the inter-assay coefficients of variation $(\mathrm{CV})$. Five replicates of the sera within each plate were also tested to calculate the intra-assay CV. Inter-assay 
variation and intra-assay variation for each sample were used to assess reproducibility of the developed assay.

\section{Estimation of serum Hsp27 levels in healthy and CMT subjects}

Indirect ELISA was conducted as described above, with different amounts of rHsp27 protein. Dilution of primary antibody was fixed (1:3200). Linear regression curve of different protein concentrations was plotted against their corresponding absorbances. Slope and intercept of the best-fit straight line were calculated to obtain the unknown concentrations of Hsp27 in the sera of healthy dogs and those afflicted with mammary tumors using the formula $Y=m X+C$, where $Y$ is the concentration of the unknown sample, $m$ is the slope of the curve, $X$ is the absorbance of the unknown sample, and $\mathrm{c}$ is the intercept of the curve. The dilution factors were also considered when estimating the concentration of serum Hsp27, which was expressed in $\mathrm{ng} / \mathrm{ml}$.

\section{Statistical analysis}

Student's $t$ test and one-way ANOVA were performed using SAS version 9.3 to check for any significant differences in the serum concentrations of Hsp27 in healthy and CMT subjects. The differences were considered significant at $p \leq 0.0001$.

\section{Results}

\section{Histopathological classification and grading of CMT}

Based on histopathological examination, CMTs were classified as simple papillary carcinoma (10\%), simple carcinoma (30\%), carcinosarcoma (20\%), and complex carcinoma (40\%) (Fig. 1a-d). Tumors mostly belonged to grade I (60\%) and grade II (40\%).

\section{Cloning, expression, and purification of rHsp27}

A band corresponding to 753 bp was resolved for $h s p 27$ gene upon PCR amplification using designed primers (Fig. 2a). The amplified product upon purification yielded a concentration of $25 \mathrm{ng} / \mathrm{ml}$. Positive clones upon NcoI and $X$ hoI RE double digestion released specific sized insert of $735 \mathrm{bp}$ (Fig. 2b). After custom sequencing of $h s p 27$, the sequence was submitted to NCBI with an accession number MG544877.

SDS-PAGE analysis of the expression kinetics revealed a high level of rHsp27 expression with a molecular weight of $27 \mathrm{kDa}$ (approximately) at $5 \mathrm{~h}$ post-IPTG induction (figure not shown here). The purified rHsp27 was resolved as a
$27 \mathrm{kDa}$ protein (approximately) upon SDS-PAGE (Fig. 3a). The concentration of the recombinant protein was found to be $0.33 \mathrm{mg} / \mathrm{ml}$ after dialysis and concentration with polyethylene glycol (PEG-20,000). The total yield of rHsp27 protein was $4.2 \mathrm{mg} / \mathrm{l}$ of the induced culture. Upon western blotting of the recombinant protein using commercially available anti-canine Hsp27 polyclonal antibodies, a specific immuno-reactivity corresponding to $27 \mathrm{kDa}$ was observed on the nitrocellulose membrane (Fig. 3b).

\section{Production of hyperimmune sera against rHsp27 in mice}

IgG purified from the hyperimmune sera was used as primary antibody. Titre of the hyperimmune sera against rHsp27 was found to be 1:1600. The optimum dilution of primary antibody after chequerboard titration was selected as 1:3200. Upon Western blot analysis of mammary tumorpositive dog serum and rHsp27 separately with the IgG purified from mice hyperimmune serum, specific bands corresponding to $27 \mathrm{kDa}$ were observed on nitrocellulose membrane (Fig. 3c), which confirmed specific reactivity of the purified $\mathrm{IgG}$ against both $\mathrm{rHsp} 27$ as well as circulating Hsp27.

\section{ROC analysis and reproducibility check of Hsp27-based indirect ELISA}

ROC analysis of the OD values revealed an area under the curve (AUC) of 0.954 for mammary tumor detection, while it was found to be 0.525 for other diseases of dogs, which indicated that the later test was less accurate and our developed assay discriminates healthy dogs from those with CMT with high accuracy, while it could not discriminate healthy dogs from those with the other diseases. At an optimal cutoff point of 0.45, the developed ELISA was found to be 96.67\% sensitive and $83.3 \%$ specific in diagnosing CMT with respect to histopathological examination. Overall ROC analysis of the developed ELISA is depicted in Fig. 4a-c and Table 1. Among the 30 CMT positive test sera samples (based on histopathology), the developed assay could differentiate 29 samples as true positive and 1 serum sample as false negative. Among the 30 test negative sera (sera from healthy dogs), 25 were designated as true negative as per the developed ELISA (Fig. 4b). The assay could not differentiate healthy dogs from those with other inflammatory diseases, lymphomas, and skin cancers, as was evident from the different attributes of ROC analysis (Fig. 4c, Table 1).

The inter-assay and intra-assay coefficients of variation were in the range of $2.56-3.82$ and $2.51-3.62 \%$, respectively (Table 2), indicating good reproducibility of the developed ELISA. 

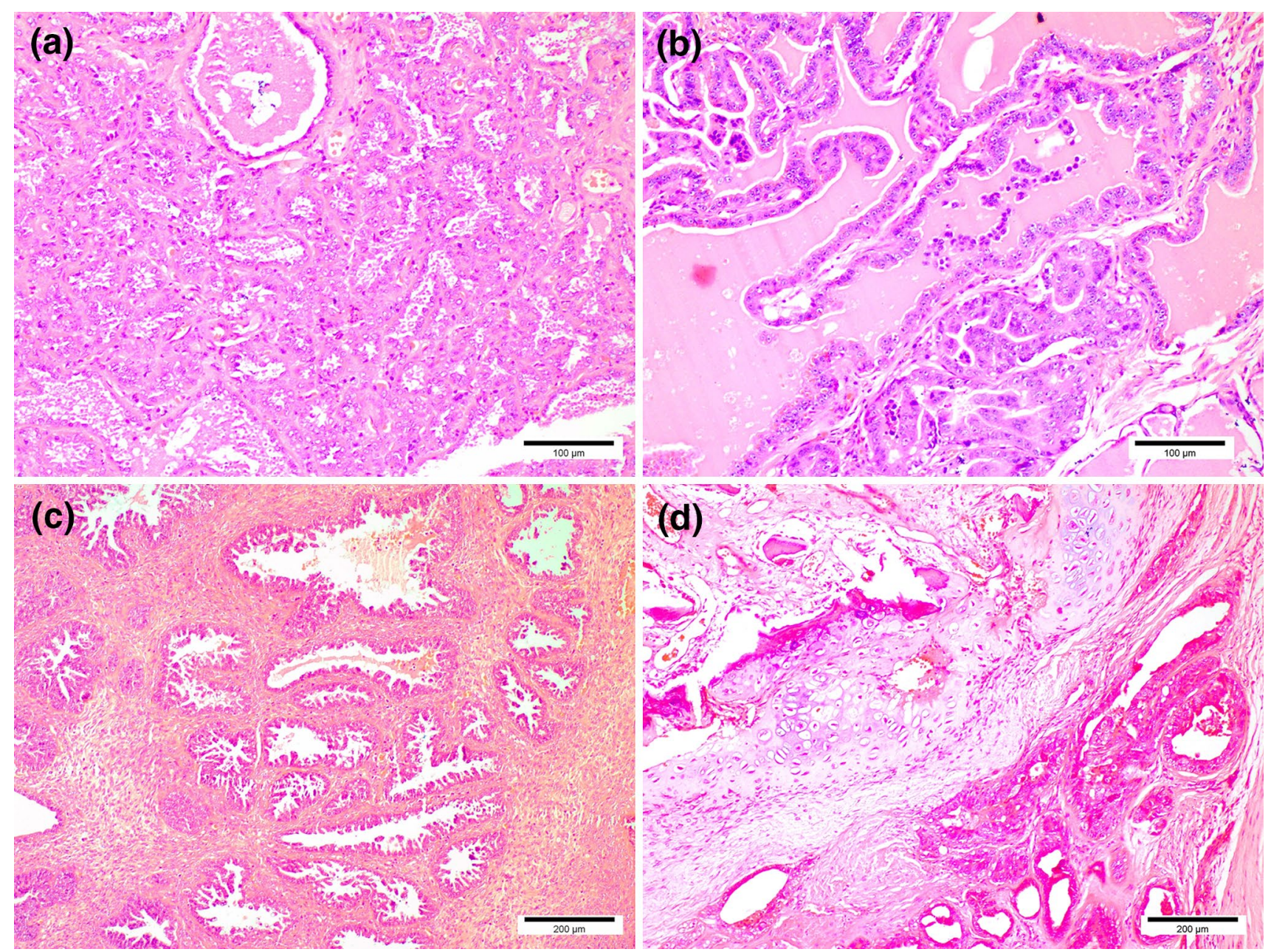

Fig. 1 a Section from canine mammary tumor showing simple carcinoma. H\&E. Magnification $\times 20$. b Section from canine mammary tumor showing simple papillary carcinoma. $H \& E$. Magnification $\times$

\section{Serum concentration of Hsp27 in tumor-free healthy dogs and CMT subjects}

Serum Hsp27 levels were found to be significantly $(p \leq 0.001)$ elevated in dogs with different types of mammary tumors $(20.33 \pm 1.23 \mathrm{ng} / \mathrm{ml})$ as compared to tumor-free apparently healthy dogs $(6.56 \pm 0.51 \mathrm{ng} / \mathrm{ml})$ (Fig. 5a). Serum concentration of Hsp27 in dogs with different histological types of mammary tumors is depicted in Fig. 5b. Irrespective of different mammary tumor histotypes, serum Hsp27 levels were significantly elevated $(p \leq 0.001)$ in all the CMT subjects which suggests that Hsp27 can serve as a marker of various types of CMT studied. However, there was a significant difference in Hsp27 concentration in dogs with different grades of CMT. The Hsp27 concentration was found to be significantly $(p \leq 0.001)$ higher in dogs with grade-II mammary tumor $\left(22.56^{\mathrm{b}} \pm 1.29\right)$ as compared to those with grade-I mammary neoplasm $\left(19.04^{\mathrm{a}} \pm 0.96\right)$.
20. c Section from canine mammary tumor showing complex carcinoma. H\&E. Magnification $\times 10$. d Section from canine mammary tumor showing carcinosarcoma. H\&E. Magnification $\times 10$

\section{Discussion}

Nowadays, the majority of the tumors are treatable provided that they are diagnosed at an earlier stage before their metastasis to distant locations. The conventional diagnostic methods of CMT rely on invasive techniques which are out-dated. Diagnosis based on serological biomarkers of tumors serves the purpose, but relying on a single biomarker for early and accurate diagnosis of CMT is implausible. Hence, need of the hour is to add a few more specific CMT biomarkers to the existing panel for accurate diagnosis and prognosis of the disease. In the last few years, our laboratory has put considerable efforts in search of markers for non-invasive diagnosis and prognosis of CMT (Sunil Kumar et al. 2013, 2018; Pandey et al. 2015, 2017, 2018; Kaur et al. 2016). Advanced research in cancer biology has shown the importance of Hsps as 


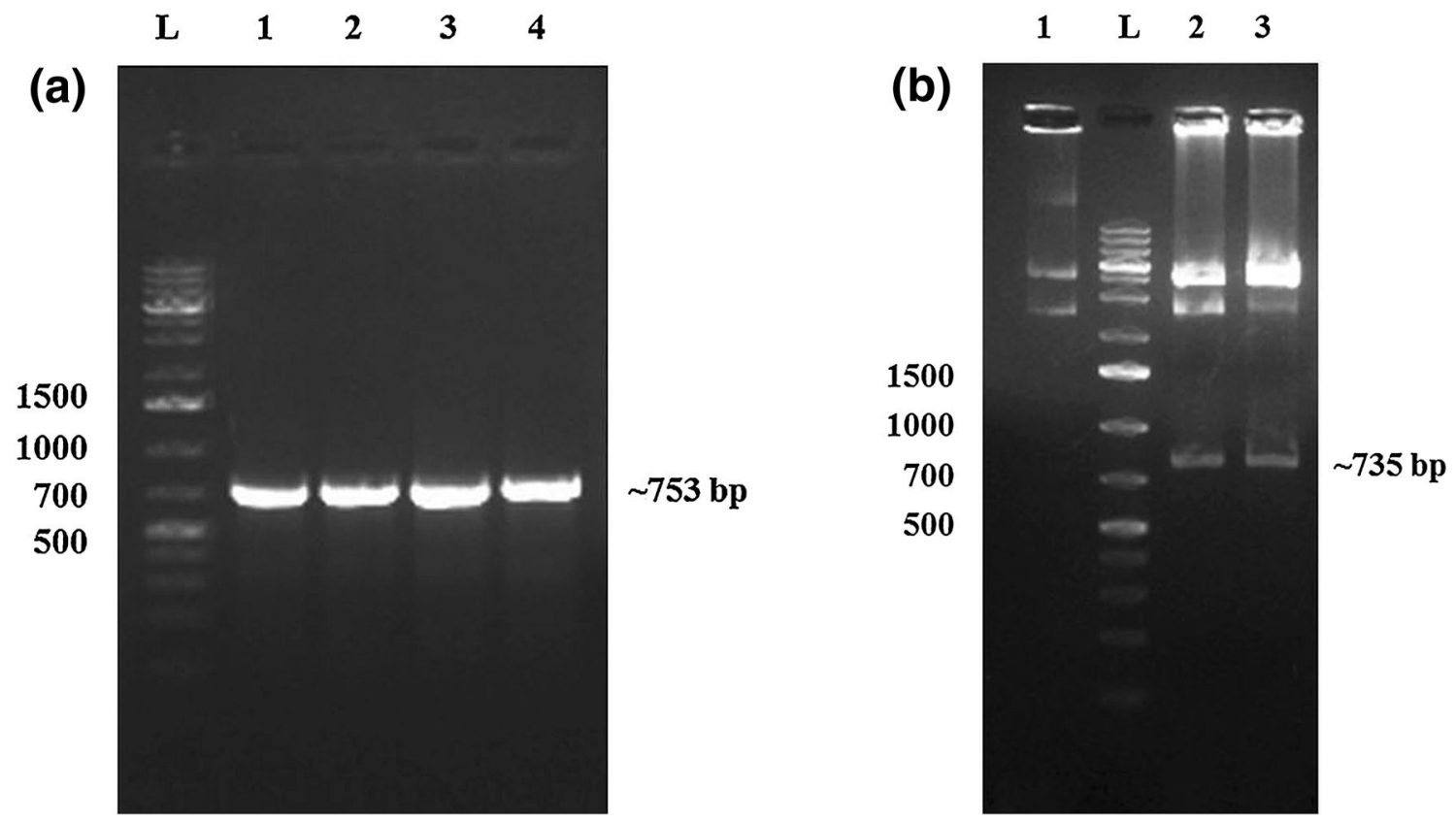

Fig. 2 a Amplification of $H s p 27$ gene from canine mammary tumor (lanes 1-4: 753 bp amplicon; lane M: $1 \mathrm{~Kb}$ plus DNA ladder). b RE digestion analysis of recombinant pProEx HTa-Hsp27 plasmid (lane
$\mathrm{L}: 1 \mathrm{~Kb}$ plus DNA ladder; lane 1: undigested plasmid, lanes 2, 3: $\mathrm{NcoI}$ and $\mathrm{XhoI}$ digested recombinant plasmids with released inserts) (a)

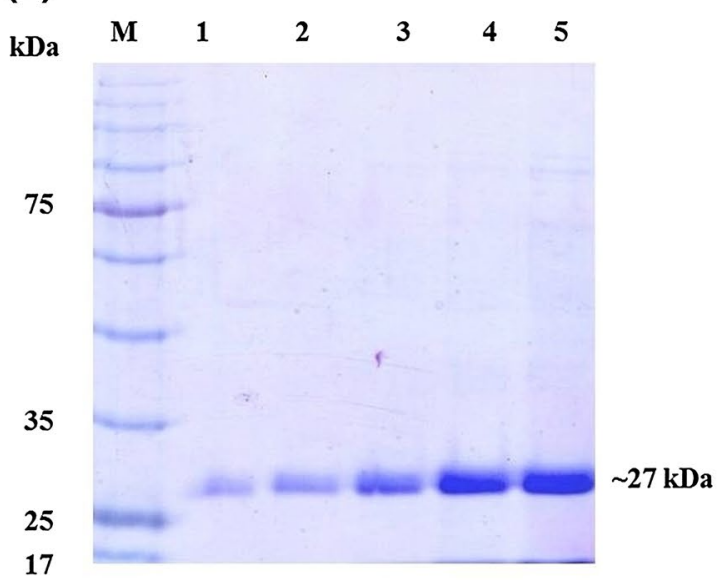

(b)

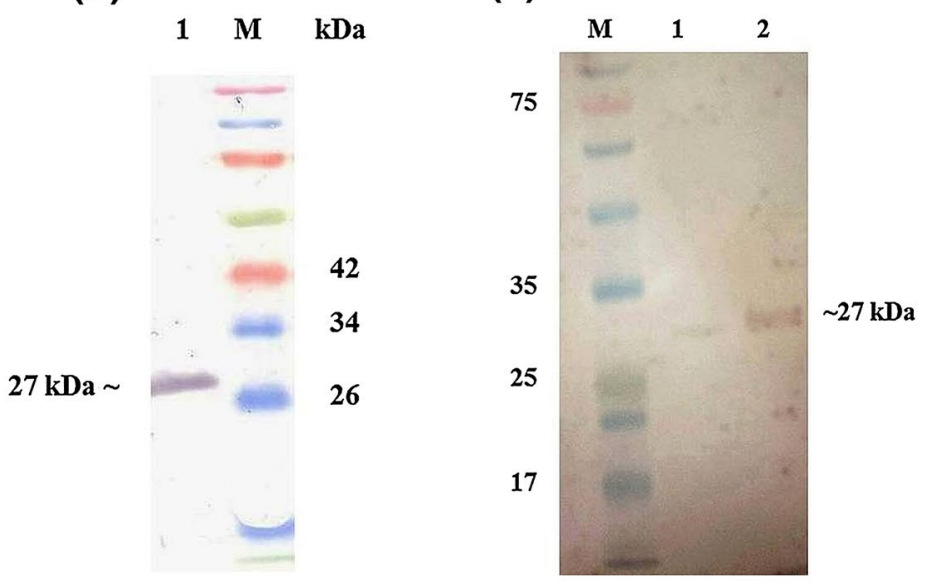

Fig. 3 a SDS-PAGE of concentrated and dialysed rHsp27 protein (lane M: prestained protein marker; lanes 1-5: purified protein). b: Western blot analysis of rHsp27 protein (lane M: prestained protein marker; lane 1: immunoreactive rHsp27)

biomarkers of carcinogenesis and their potential in prognosis of some human cancer types (Salda and Romanucci 2012).

Apart from playing a vital role in protein folding and oxidative stress, Hsp27 also possesses anti-apoptotic function (Concannon et al. 2003). During tumor development, its expression is up-regulated which protects the cancer cells from apoptosis by interfering with key components of apoptosis signaling pathways (Kuramitsu 2012). In breast cancer cells, signal transducer and activator of transcription 3 (STAT-3), classified as an oncogene, is constitutively activated. Activated STAT-3 leads to up-regulation of Hsp27 (Song et al. 2004) which, in turn, prevents the induction of apoptosis and helps the breast cancer cells to survive and increases their metastatic potential (Kuramitsu 2012). Hsp27 is one such chaperone that is up-regulated not only at the onset of human breast cancer but also in 

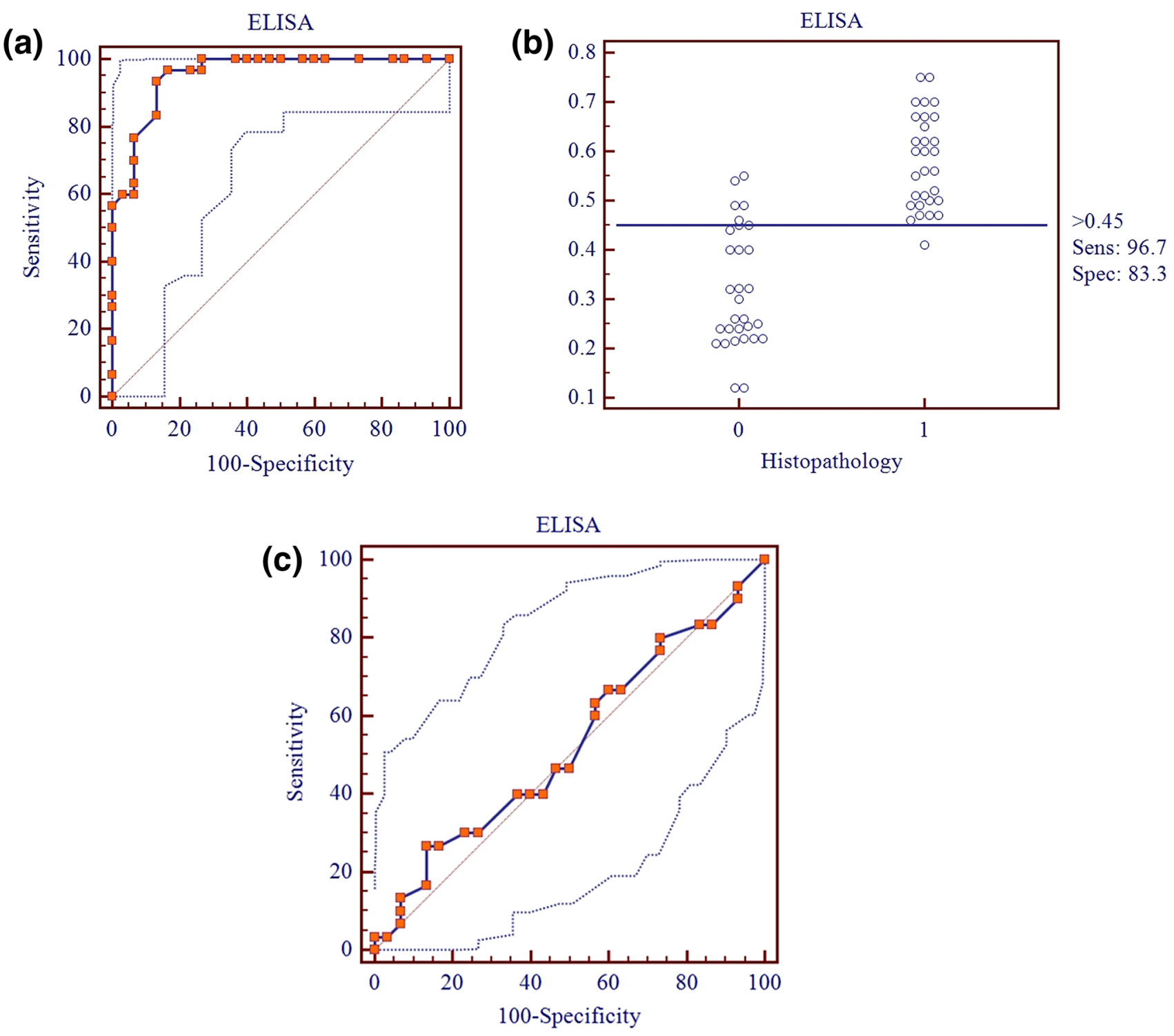

Fig. 4 a ROC curve for rHsp27-based ELISA for detecting canine mammary tumor. b ROC analysis-based estimation outcomes for rHsp27-based ELISA for canine mammary tumor detection (0 histo- pathology tumor negative; 1 histopathology tumor positive). c ROC curve for rHsp27-based ELISA for detecting the other canine diseases
CMT, and plays an important role in its progression (Vahid et al. 2016; Romanucci et al. 2006).

In our study, a detectable level of circulating Hsp27 was observed in the sera of CMT subjects, indicating that Hsp27 is a secretory protein and can be detected in the sera of canines afflicted with mammary tumor. The developed assay, however, could not distinguish healthy dogs from those with other inflammatory diseases or neoplasia. Our results corroborate with the earlier findings in women with breast cancer, where serum Hsp27 has been reported to be elevated (De and Roach 2004). Over-expression of Hsp27 has also been associated with poor prognosis of various types of cancers in human beings including breast and prostate (Vahid et al. 2016; Kang et al. 2008; Ciocca and Calderwood 2005). Hsp27 over-expression has also been reported to promote proliferation, migration, and increased doxorubicin resistance in a CMT cell line, DTK-F (Lin et al. 2015), suggesting that Hsp27 induces doxorubicin resistance in CMT. A high correlation between Hsp27 expression and tumor invasiveness in association with reduced overall survival has also been reported in malignant canine mammary neoplasia (Romanucci et al. 2006).

In the past, serum levels of Hsp27 (sHsp27) have also been studied in human patients with hepatocellular carcinoma. An Hsp27 cut-off value of 456.5 pg/ml was considered in differentiating the diseased subjects from healthy 
Table 1 ROC analysis of rHsp27-based ELISA for diagnosing canine mammary tumor and other diseases of dogs

\begin{tabular}{lll}
\hline Overall ROC analysis & $\begin{array}{l}\text { rHsp27-based ELISA for canine } \\
\text { mammary tumor detection }\end{array}$ & $\begin{array}{l}\text { rHsp27-based ELISA for } \\
\text { detection of other canine } \\
\text { diseases }\end{array}$ \\
\hline AUC & 0.954 & 0.525 \\
AUC at 95\% CI & $0.867-0.991$ & $0.392-0.656$ \\
Standard error & 0.0236 & 0.0758 \\
$P$ value for null hypothesis AUC $=0.50$ & 0.0001 & 0.7416 \\
Optimal test cut-off & 0.45 & 0.45 \\
Positive likelihood ratio (+LR) & 5.80 & 1.60 \\
Negative likelihood ratio (-LR) & 0.04 & 0.88 \\
Sensitivity (\%) & 96.67 & 26.67 \\
Specificity (\%) & 83.33 & 83.33 \\
Test positive predictive value (\%) & 85.3 & 61.5 \\
Test negative predictive value (\%) & 96.2 & 53.2 \\
\hline
\end{tabular}

Table 2 Reproducibility of the rHsp27-based ELISA

\begin{tabular}{llllll}
\hline Serum samples & 1 & 2 & 3 & 4 & 5 \\
\hline Intra-assay CV\% (mean) & 3.62 & 2.51 & 3.12 & 2.56 & 3.25 \\
Inter-assay CV\% (mean) & 3.82 & 3.14 & 2.56 & 2.57 & 3.56 \\
\hline
\end{tabular}

control with a test sensitivity and specificity of $70 \%$ and 73\%, respectively (Gruden et al. 2013). However, till date, serum levels of Hsp27 in dogs with CMT have not been determined. Our study, for the first time, attempts to estimate the serum concentration of Hsp27 in CMT subjects employing rHsp27-based indirect ELISA. Our results are efficient enough to differentiate the healthy dogs from those with mammary tumors. Thus, Hsp27 can act as a serological biomarker for the non-invasive diagnosis and prognosis of

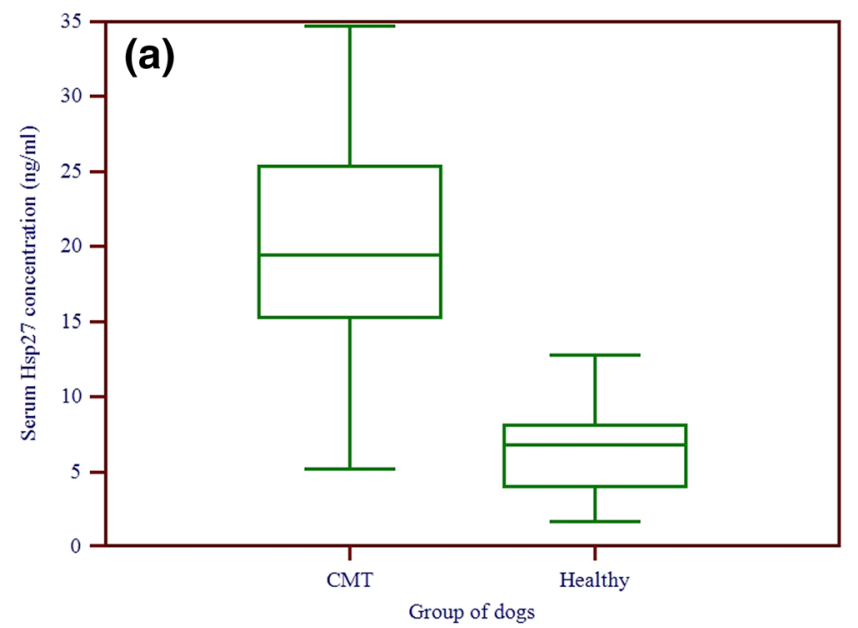

Fig. 5 a Box and Whisker's plots depicting serum Hsp27 concentrations in healthy dogs and those with mammary tumors. b Box and Whisker's plots depicting serum Hsp27 concentrations in dogs with the malady, and could be used to assess the treatment success, as well. However, owing to the smaller sample size in the current study, the data need to be confirmed in a study employing a large number of CMT subjects and healthy controls in future.

\section{Conclusion}

Our study is the first to report the over-expression and secretion of Hsp27 in dogs with mammary tumors. The developed rHsp27-based indirect ELISA had a high specificity (83.3\%) and sensitivity (96.6\%) in discriminating healthy dogs from those with mammary tumor. Therefore, Hsp27 can be exploited as one of the 'neoplastic signatures' of canine mammary tumors. Serum Hsp27 concentration was found to

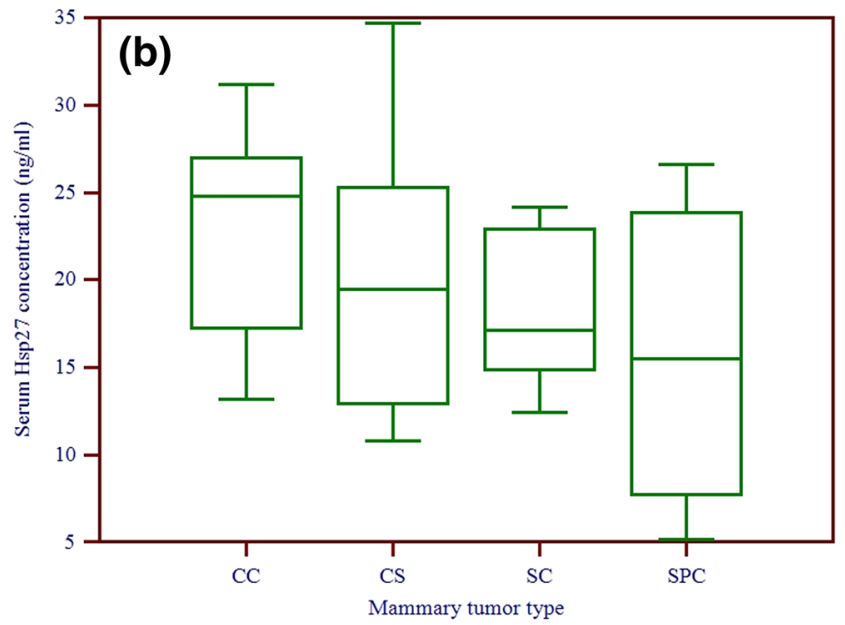

different types of mammary tumors ( $C C$ complex carcinoma, $C S$ carcinosarcoma, $S C$ simple carcinoma, $S P C$ simple papillary carcinoma) 
be significantly elevated in all CMT subjects irrespective of the tumor histotypes as compared to healthy dogs. Adding Hsp27 to the current panel of CMT biomarkers will certainly improve the sensitivity and specificity of CMT diagnosis.

Acknowledgements The authors are thankful to the Department of Biotechnology, India, for providing funds to carry out the research work (BT/PR6434/GBD/27/414/2012).

\section{Compliance with ethical standards}

Conflict of interest We declare that there is no conflict of interest regarding the publication of this article.

\section{References}

Bongiovanni L, Romanucci M, Malatesta D, Andrea A, Ciccarelli A, Salda L (2014) Survivin and related proteins in canine mammary tumors: immunohistochemical expression. Vet Pathol 52(2):269-275

Bruey JM, Ducasse C, Bonniaud P, Ravagnan L, Susin SA, Diaz LC, Gurbuxani S, Arrigo AP, Kroemer G, Solary E, Garrido C (2000) Hsp27 negatively regulates cell death by interacting with cytochrome-c. Nat Cell Biol 2:645-652

Calderwood SK (2010) Heat shock proteins in breast cancer progression a suitable case for treatment? Int $\mathbf{J}$ Hyperthermia 26(7):681-685

Calderwood SK, Stevenson HA, Murshid A (2012) Heat shock proteins, autoimmunity, and cancer treatment. Autoimmune Dis. https ://doi.org/10.1155/2012/486069

Chomczynski P, Sacchi N (1987) Single-step method of RNA isolation by guanidinium thiocyanate-phenol-chloroform extraction. Anal Biochem 162:156-159

Ciocca DR, Calderwood SK (2005) Heat shock protein in cancer: diagnostic, prognostic, predictive and treatment implication. Cell Stress Chap 10(2):86-103

Concannon CG, Gormann AM, Samali A (2003) On the role of Hsp27 in regulating apoptosis. Kluwer Acad Publ 8(1):61-70

De AK, Roach SE (2004) Detection of the soluble heat shock protein 27 (hsp27) in human serum by an ELISA. J Immunoassay Immunochem 25(2):159-170

Goldschmidt M, Pena L, Rasotto R, Zappulli V (2011) Classification and grading of canine mammary tumor. Vet Pathol 48(1):117-131

Greiner M, Pfeiffer D, Smith RD (2000) Principles and practical application of the receiver-operating characteristic analysis for diagnostic tests. Prev Vet Med 45(1-2):23-41

Gruden G, Carucci P, Lolli V, Cosso L, Dellavalle E, Rolle E, Cantamessa A, Pinach S, Abate ML, Campra D, Brunello F, Bruno G, Rizzetto M, Perin PC (2013) Serum heat shock protein 27 levels in patients with hepatocellular carcinoma. Cell Stress Chap 18(2):235-241

Kang SH, Kang KW, Kim KH, Kwon B, Kim SK, Lee HY, Kong SY, Lee S, Jangs G, Yoo BC (2008) Upregulated HSP27 in human breast cancer cells reduces Herceptin susceptibility by increasing Her2 protein stability. BMC Cancer 8:286

Kaur N, Sunil Kumar BV, Mahajan K, Singh S (2016) Expression and characterization of tissue inhibitor of metalloproteinase 4 from complex canine mammary carcinomas. J Immunoassay Immunochem 37:515-526
Kuramitsu Y (2012) Is Hsp27 a key molecule or biomarker for cancer? J Gastroint Dig Syst 2:1-12

Laemmli UK (1970) Cleavage of structural protein during the assembly of the head bacteriophage T4. Nature 227:680-685

Lin AC, Lioo CW, Lin SW, Huang CY, Liou CJ, Lai U (2015) Canine heat shock protein 27 promotes proliferation migration and doxorubicin resistance in the canine cell line DTK-F. Vet J 203(2):254-262

Misdrop W, Else RW, Helmen E, Lipscomb TP (1999) Histological classification of the mammary tumor of the dog and cat. In: Shulman, WHO International Histological classification of tumor of domestic animals, Second series, Armed Forces Institute of Pathology, Washington DC vol 7, pp 16-29

Moe L (2001) Population based incidence of mammary tumor in some breads of dogs. J Reprod Fertil Suppl 57:439-443

Pandey M, Sunil Kumar BV, Verma R (2015) Mammaglobin as a diagnostic serum marker of complex canine mammary carcinoma. Res Vet Sci 103:187-192

Pandey M, Sunil Kumar BV, Singh S, Verma R (2017) Development of recombinant matrix metalloproteinase-3 based sandwich ELISA for sero-diagnosis of canine mammary carcinomas. J Immunoassay Immunochem 38(1):34-44

Pandey M, Sunil Kumar BV, Gupta K, Sethi RS, Kumar A, Verma R (2018) Over-expression of mammaglobin-B in canine mammary tumors. BMC Vet Res 14:184-190

Romanucci M, Marinelli A, Sarli G, Della LS (2006) Heat shock proteins expression in canine malignant mammary tumours. BMC Cancer 6:171-175

Salda DL, Romanucci M (2012) The role of heat shock proteins in mammary neoplasms: a brief review. J Cancer Ther 3:755-767

Sambrook J, Russell DW (2001) Molecular cloning: a laboratory manual, 3rd edn. Cold Spring Harbor, New York

Simioni BM, De TA, Hammann A, Joly AL, Bossis G, Fourmaux E, Bouchot A, Landry J, Piechaczyk M, Garrido C (2009) Heat shock protein 27 is involved in SUMO-2/3 modification of heat shock factor 1 and thereby modulates the transcription factor activity. Oncogene 28(37):3332-3344

Song H, Ethier SP, Dziubinski ML, Lin J (2004) Stat3 modulates heat shock $27 \mathrm{kDa}$ protein expression in breast epithelial cells. Biochem Biophys Res Comm 314(1):143-150

Sunil Kumar BV, Kataria M (2013) Identification of single nucleotide polymorphism in stromelysin-3 catalytic domain in canine mammary tumors. J App Anim Res 41(3):366-369

Sunil Kumar BV, Kumar KA, Padmanath K, Saxena M, Sharma B, Kataia M (2013) Development of recombinant matrix metalloproteinase-11 based sandwich ELISA for the diagnosis of canine mammary tumor. Proc Natl Acad Sci India Sec B Biol Sci 83(2):181-185

Sunil Kumar BV, Bhardwaj R, Mahajan K, Kashyap N, Kumar A, Verma R (2018) The overexpression of HSP90B1 is associated with tumorigenesis of canine mammary glands. Mol Cell Biochem 440:23-31

Talwar GP (1983) A handbook practical immunology. Vikash, New Delhi, pp 71-83

Towbin H, Stachelin T, Gordon J (1979) Electrophoresis transfer of protein from polyacrylamide gels to nitrocellulose sheets. Procedure and applications. Proc Natl Acad Sci USA 76:4350-4354

Vahid S, Thaper D, Gibson KF, Bishop JL, Zoubeidi A (2016) Molecular chaperone Hsp27 regulates the Hippo tumor suppressor pathway in cancer. Sci Rep 6:31842 